\title{
Investigating the Durability of Concrete Filled with Different Ratio's of Glass Fibre
}

\author{
Er. Sunny Rana \\ Research Scholar, Dept. of Civil Engineering. \\ Indo-global group of Colleges. \\ Abhipur, Mohali, India
}

\begin{abstract}
Concrete is one of the most widely recognized development material for the most part delivered by utilizing locally accessible ingredients. The development of concrete has brought about the essential need for additives both chemical and mineral to improve the performance of concrete. Hence varieties of admixtures such as fly ash, coconut fibre have been used so far. Hence an attempt has been made in the present investigation to study the behaviour of glass fibre in concrete. The present trend in concrete technology is towards increasing the strength and durability of concrete to meet the demands of the modern construction. The main aim of the study is to study the effect of glass fibre in the concrete. Glass fibre has the high tensile strength and fire resistant properties thus reducing the loss of damage during fire accidents. The addition of these fibres into concrete can dramatically increase the compressive strength, tensile strength and split tensile strength of the concrete. In this study, tests have done for the concrete with glass fibre of $0.5 \%, 1 \%, 2 \%$ and $3 \%$ of cement by adding as an admixture. Durability of concrete can also be checked by evaluation of alkalinity and acid curing of sample.
\end{abstract}

Key words: Fly Ash, coconut fibre, Glass fibre, Durability, Tensile strength, Fire resistant, Split tensile strength.

\section{INTRODUCTION}

Glass fiber has used over 30 years in several construction elements, mainly non constructional ones, like façade panels, piping for sanitation, decorative non recoverable form work and other products. Concrete is one of the most durable building materials. It provides superior fire resistance compared with wooden construction and gains strength over time. Structures made of concrete can have a long service life. Concrete is used more than any other manmade material in the world Concrete, has relatively high compressive strength, but much lower tensile strength. - Concrete has a very low coefficient of thermal expansion and shrinks as it matures. All concrete structures crack to some extent, due to shrinkage and tension. Glass fiber concrete (GFC) consists basically of a matrix composed of cement, sand, water, and admixtures, in which short length glass fibers are dispersed. The effect of the fibers in this composite leads to an increase in the tension and impact strength of the material.

Glass is a useful material due to its high ratio of surface area to weight. Because of this the augmented surface area makes them much more vulnerable to chemical attack. By entrapping air, blocks of glass fibre make good thermal insulation with a thermal conductivity of order of 0.05 $\mathrm{w} /(\mathrm{mk})$. The strength of the glass fibre is usually tested and

\author{
Er. Kiran Talwar \\ Assistant Prof, Dept. of Civil Engineering \\ Indo-global group of Colleges \\ Abhipur, Mohali. India
}

reported for "virgin" or pristine fibres those which have just been manufactured. The freshest, thinnest fibres are more ductile. The more the surface is scratched, the less the resulting tenacity. As the glass possesses an amorphous structure, its properties are the same in all directions. Humidity is an important factor in the tensile strength. Moisture is easily adsorbed. Therefore it can worsen microscopic cracks and surface defects, and lessen tenacity. Unlike carbon fiber, glass can suffer more elongation before it breaks. A correlation exists between bending diameter of the filament and the filament diameter. The viscosity of the molten glass is very important manufacturing success. While drawing i.e., pulling of the glass to reduce fibre circumference, the viscosity has to be relatively low. If it is too high, the fiber will break during drawing. If the viscosity is too low, the glass will end up in droplets rather than being drawn out into fibre.

Concrete is prepared with locally available materials. It is also very popular in construction. Therefore to modify the performance of concrete it is essential to add both chemical and mineral additives such as fly ash, silica fume, different types of fibres, etc. Therefore in the present investigation an attempt has been made to study the behaviour of concrete in which fly ash and glass fibre have been added. The present trend in concrete technology is increasing its strength and durability. This is essential to meet the demands of the modern construction. The main aim of the study is to study the effect of glass fibre which has high tensile strength and fire resistant properties. Concrete containing glass fibre diminishes the loss of damage during fire accidents. The results of addition of these fibres into concrete are far fetching in the sense it dramatically increases the compressive strength, tensile strength and split tensile strength of the concrete.

Key words: glass powder, Portland cement concrete, Glass fiber concrete, amorphous structure, fly ash, durability, tensile strength, split tensile strength.

\section{LITERATURE REVIEW}

Adarsh Dubey, Sanjay Saraswat and Devansh Jain (2016)Glass is a transparent material produced by melting a mixture of materials such as silica, soda ash, and $\mathrm{CaCO} 3$ at high temperature followed by cooling where solidification occurs without crystallization. Glass is widely used in our lives through manufactured products such as sheet glass, bottles, glassware, and vacuum tubing. 
Glass is an ideal material for recycling. The use of recycled glass saves lot of energy and the increasing awareness of glass recycling speeds up focus on the use of waste glass with different forms in various fields. One of its significant contributions is the construction field where the waste glass was reused for concrete production. The application of glass in architectural concrete still needs improvement. Several study have shown that waste glass that is crushed and screened is a strong, safe and economical alternative to sand used in concrete. During the last decade, it has been recognized that sheet glass waste is of large volume and is increasing year by year in the shops, construction areas and factories.

J.M. Khatib, E.M. Negim, H.S. Sohl and N. Chileshe, (2014) Glass is commonly used in building / construction industries and large amount of glass is powdered daily. The disposal of waste glass is an environmental issue as waste glass causes disposal problem. Today the construction industry is in need of finding cost effective materials for increasing the strength of concrete structures. Glass powder finer than $600 \mu$ is reported to have pozzolanic behaviour. An attempt is made to investigate the possibility of using the waste glass powder as the partial replacement of ordinary Portland cement in concrete. Concrete with replacement of cement by waste glass powder such as $5 \%$, $10 \%, 15 \%$ and $20 \%$ were produced and properties of this concrete has been compared with concrete of control mix with no replacement. Cube specimens of 24 numbers were cast, cured and tested for 7 day and 28 days strength. Compression test was conducted and the results were compared. The findings revealed an increase in compressive strength with the increase in the replacement of cement by glass powder. To reduce the demand for cement, glass powder replacements can be adopted. The replacement of glass powder decreases the unit weight as well as the porosity as indicated by the decrease in water absorption. It reduces the quantity of cement to be used in concrete. Also glass powder is proved to be economical and is considered as environmental friendly construction material.J.M. Khatib, E.M. Negim, H.S. Sohl and N. Chileshe, (2014) Glass is commonly used in building / construction industries and large amount of glass is powdered daily. The disposal of waste glass is an environmental issue as waste glass causes disposal problem. Today the construction industry is in need of finding cost effective materials for increasing the strength of concrete structures. Glass powder finer than $600 \mu$ is reported to have pozzolanic behaviour. An attempt is made to investigate the possibility of using the waste glass powder as the partial replacement of ordinary Portland cement in concrete. Concrete with replacement of cement by waste glass powder such as 5\%, 10\%, 15\% and $20 \%$ were produced and properties of this concrete has been compared with concrete of control mix with no replacement. Cube specimens of 24 numbers were cast, cured and tested for 7 day and 28 days strength. Compression test was conducted and the results were compared. The findings revealed an increase in compressive strength with the increase in the replacement of cement by glass powder. To reduce the demand for cement, glass powder replacements can be adopted. The replacement of glass powder decreases the unit weight as well as the porosity as indicated by the decrease in water absorption. It reduces the quantity of cement to be used in concrete. Also glass powder is proved to be economical and is considered as environmental friendly construction material. Madandoust Rahmat, Ghavidel Reza (2013).The objective was to make use of the combination of waste glass powder (GP) and rice husk ash (RHA) as replacement for Portland cement. Hybrid mixtures containing 0-20\% GP and 0-20\% RHA were prepared. The best values of replacements by GP and RHA, based on the 28-days compressive strength and strength activity index, were determined as $10 \%$ and $5 \%$, respectively. From these results, the properties of hybrid concrete tended to increase with age due to the development of higher pozzolanic activity. The results also revealed good evidence that both GP and RHA can be used together in concrete without any adverse effects. Balandis A, Vaickelionis G. (2012) One kind of the most abundant glass defects is cord. Cord is the place of concentration of internal stress in the glass and that reduce mechanical and thermo mechanical strength of glass. The reasons of cords formation can be different. The origin of cords formation is commonly examined only by indirect modeling methods of formation processes and its mechanisms. The determination of cords formation reasons is especially important for the production of electro vacuum glass, when the rate of change of the temperature of glass details is big. In this work a new kind of glass defect - thread type cord, which forms in the central part of screen - is determined and examined. The formation of this cord can be explained by heterogeneous crystallization of glass on the surface of plunger solid phase, when plunger vertically gains height. The problems of homogenization of glass melt in the feeder channel also have been discussed. Mageswari M, Vidivelli B (2010) Sheet glass powder (SGP) used in concrete making leads to greener environment. In shops, nearby Chidambaram many sheet glass cuttings go to waste, which are not recycled at present and usually delivered to landfills for disposal. Using SGP in concrete is an interesting possibility for economy on waste disposal sites and conservation of natural resources. This paper examines the possibility of using SGP as a replacement in fine aggregate for a new concrete. Natural sand was partially replaced $(10 \%, 20 \%, 30 \%, 40 \%$ and $50 \%)$ with SGP. Compressive strength, Tensile strength (cubes and cylinders) and Flexural strength up to 180 days of age were compared with those of concrete made with natural fine aggregates. Fineness modulus, specific gravity, moisture content, water absorption, bulk density, \%voids, \% porosity (loose and compact) state for sand (S) and SDA were also studied. The test results indicate that it is possible to manufacture concrete containing Sheet glass powder (SGP) with characteristics similar to those of natural sand aggregate concrete provided that the percentage of SGP as fine aggregate is limited to $10-20 \%$, respectively. I. B. Topcu and M. Canbaz, (2007). The Present study was carried out to evaluate the influence of addition of Fibres and Class 
' $C$ ' Flyash on the mechanical properties of concrete. Fibre Reinforced Concrete (FRC) is very useful in extreme climate where shrinkage of concrete causes cracks. The Fibre Reinforced Flyash concrete (FRFAC) has been successfully used to minimize cavitations / damages in hydraulics structures. The FRC with and without Fly ash was tested with the fraction of volume of the steel Fibre in concrete which varied from 0.0 to $1.0 \%$. For determining, the compressive strength \& permeability cubes of $150 \mathrm{~mm}$ size were prepared. Nine cubes of each series were prepared; out of nine, three were used for determining the strength \& permeability of cracked \& un-cracked concrete. The formation of additional calcium silicate hydrates in the hydrated cement matrix because of the addition of fly ash in FRFAC results in its improved characteristics. The initial tangent modulus of FRC and FRFAC is found to be independent of the quantity of Fibers. The experimental investigation shows that the increase in the Fibre content increases the compressive strength, crushing strain and Poisson's Ratio of FRC and FRFAC. While increasing the Fibre content, the permeability of concrete reduced. The mode of cracking has been discussed. Shi, C. and K. Zheng,( 2007). The use of recycled waste glasses in Portland cement and concrete has attracted a lot of interest worldwide due to the increased disposal costs and environmental concerns. Being amorphous and containing relatively large quantities of silicon and calcium, glass is, in theory, pozzolanic or even cementitious in nature when it is finely ground. Thus, it can be used as a cement replacement in Portland cement concrete. The use of crushed glasses as aggregates for Portland cement concrete does have some negative effect on properties of the concrete; however, practicle applicability can still be produced even using $100 \%$ crushed glass as aggregates. The main concerns for the use of crushed glasses as aggregates for Portland cement concrete is the expansion and cracking caused by the glass aggregates. This paper summarizes the progresses and points out the directions for the proper uses of waste glasses. Sobolev K., Turker P., Soboleva S., Iscioglu G., (2006) Waste glass creates a serious environmental problem, mainly because of the inconsistency of the waste glass streams. The use of waste glass as a finely ground mineral additive (FGMA) in cement is a promising direction for recycling. Based on the method of mechano-chemical activation, a new group of ECO-cements was developed. In ECO-cement, relatively large amounts (up to 70\%) of Portland cement clinker can be replaced with waste glass. This report examines the effect of waste glass on the microstructure and strength of ECO-cement based materials. Scanning electron microscopy (SEM) investigations were used to observe the changes in the cement hydrates and interface between the cement matrix and waste glass particles. According to the research results, the developed ECO-cement with $50 \%$ of waste glass possessed compressive strength properties at a level similar to normal Portland cement. V. Corinaldesi, G. Gnappi, G. Moriconi, and A. Montenero (2005) This work was aimed at studying the possibility of reusing waste glass from crushed containers and building demolition as aggregate for preparing mortars and concrete. At present, this kind of reuse is still not common due to the risk of alkali-silica reaction between the alkalis of cement and silica of the waste glass. This expansive reaction can cause great problems of cracking and, consequently, it can be extremely deleterious for the durability of mortar and concrete. However, data reported in the literature show that if the waste glass is finely ground, under 75mum, this effect does not occur and mortar durability is guaranteed. Therefore, in this work the possible reactivity of waste glass with the cement paste in mortars was verified, by varying the particle size of the finely ground waste glass. No reaction has been detected with particle size up to 100 mum thus indicating the feasibility of the waste glass reuse as fine aggregate in mortars and concrete. In addition, waste glass seems to positively contribute to the mortar micro-structural properties resulting in an evident improvement of its mechanical performance.Ahmad Shayan (2004) A large proportion of the postconsumer glass is recycled into the packaging stream again, and some smaller proportions are used for a variety of purposes, including concrete aggregate. However, a significant proportion, which does not meet the strict criteria for packaging glass, is sent to landfill, taking the space that could be allocated to more urgent uses. Glass is unstable in the alkaline environment of concrete and could cause deleterious alkali-silica reaction (ASR) problems. This property has been used to advantage by grinding it into a fine glass powder (GLP) for incorporation into concrete as a pozzolanic material. In laboratory experiments, it can suppress the alkali reactivity of coarser glass particles as well as that of natural reactive aggregates. It undergoes beneficial pozzolanic reactions in the concrete and could replace up to $30 \%$ of cement in some concrete mixes with satisfactory strength development. The drying shrinkage of the concrete containing GLP was acceptable. Chesner W.H, Coollins R.J \& Mackay M.H 1998. The objective of this project was to develop a concise, easy-to-use manual containing the latest available information on the use of waste or by-product materials in pavement construction applications. The manual provides technical guidance for highway and materials engineers, waste and by-product generators, and others involved in making decisions regarding the use of waste and by-product materials in highway construction. The manual covers nineteen waste and by-product materials from the domestic, industrial, and mining sectors and six highvolume pavement construction applications. For each material, information on material origin, sources, and properties is provided. In addition, application-specific information (for specific material-application combinations) is provided, including past performance, engineering properties, processing requirements, design and construction, and unresolved issues. General guidance on environmental and cost issues, and a general outline on determining the suitability of a material in an application, are also provided. The manual is distributed in loose-leaf format for ease of use and to allow future updates and expansion. 


\section{OBJECTIVE OF THE STUDY}

- Determine the optimum waste glass content to be added as a partial replacement of cement.

- To determine an optimum mix proportion of cement, Fine ground Glass Waste, Sand, Coarse Aggregate and Water-Cement ratio for a given grade of concrete.

- To determine the mechanical and chemical properties of the optimized concrete.

- To economically compare conventional concrete with the concrete modified using glass waste.

- Review the merits of using fibered waste glass as a supplementary cementitious material, replacing a portion of the cement fiber used.

- Study the influence of waste glass on hardened and fresh properties of concrete mixes.

- Utilization of industrial waste in a useful manner in cement production and diverting a waste material from landfills.

- Protect the environment by the use of industrial waste in concrete in order to improve the environmental impact of the concrete industry by reducing the greenhouse gases produce

\section{METHODOLOGY}

\section{a) Fineness Test}

The fineness of cement is very significant and plays an important role on the rate of hydration and hence on the rate of gain of strength and also on the rate of evaluation of heat. The surface area of finer cement is larger for hydration and hence it helps achieve a faster development of strength. The fineness of grading has increased over the year. But now it has nearly stabilized. Different cements are ground to different finenesses. Maximum number of particle in a sample of cement should have a size of less than about 100 micron. The smallest particle is a size of about 10 micron. The particle size fraction below 3 micron has been found to have predominant effect on the strength at one day while 325 micron fraction to have a major influence on the 28 days strength. It was observed that increase in fineness of cement was also found to increase the shrinkage of concrete. In commercial cement it is suggested that there should be about 25-30 percent of particle of less than 7 micron in size. Fineness of cement is tested in two ways.

- By sieve

- By air permeability method

b) Standard Consistency Test

$400 \mathrm{gm}$ of cement was weighed and it was first mixed with $25 \%$ of water by its weight and filled in Vicat mold within five minutes. Now the mould was placed on the glass plate and it was filled with paste further and shaken to expel the entrapped air, if any. The surface of the paste was leveled on the top of the mould with trowel. The plunger was then made to touch the surface of the paste and was allowed to fall under its own weight.

When the plunger comes to rest, the depth of penetration was noted. When the plunger was at a depth of $33 \mathrm{~mm}-37 \mathrm{~mm}$ from top the percentages of water added was correct and this percentage of water was taken as the consistency of cement. If not,

the test was repeated by taking the fresh sample and mixed with water increasing its content by 1 percentage.

\section{c) Setting Time Test}

Initial setting time is regarded as the time elapsed between the moment the water is added to the cement to the time that the paste starts its plasticity. The final setting time is the time that elapsed between the moment the water is added to the cement and the time the paste has completely lost its plasticity and has attained sufficient firmness to resist certain definite pressure.

\section{d) Initial Setting Time of $O P C$}

The mould and the non-porous plate were washed, cleaned and dried. $400 \mathrm{gm}$ of the given sample of cement were taken on the non-porous plate. The volume of water taken was 0.85 times of water required for standard consistency which was then added very carefully to dry cement, and mixed thoroughly to form a neat cement paste. The mixing was completed within 3 - 5 minutes from the time water was added to cement. At the instance of adding water to the cement, the time taken was noted by using a stop watch. The Vicat mould was placed on the non-porous plate and was filled with the prepared cement paste and the surface of paste was made smooth in level with the top of the mould by using a trowel. By shaking the mould slightly, air if any was expelled from the sample. The non-porous plate and mould were placed under the needle.

\section{e) Final Setting Time of OPC}

In this case the annular attachment replaces the needle used in this test. The attachment was let down rapidly permitting it to penetrate into the paste. When the attachment comes to rest, the reading on the index scale was recorded. At every 30 seconds the procedure of releasing the needle was repeated till the reading on the index scale showed $5 \pm 5 \mathrm{~mm}$ from the bottom of the mould. The releasing the needle was continued at every 2 min till the needle made an impression on the test block.

\section{f) Specific Gravity of Cement}

Indian Standard Specification IS:2386 (1963b) recommends various procedures to find out the specific gravity of different sizes of aggregates. A sample of aggregates less than $2 \mathrm{~kg}$ is taken. In order to remove the finer particle and dust adhering to the aggregates it is thoroughly washed. Later it is placed in a wire basket and submerged in distilled water at a temperature between $22^{\circ} \mathrm{C}$ to $33^{\circ} \mathrm{C}$. Entrapped air is removed from the sample by lifting the basket containing it $25 \mathrm{~mm}$ above base of the tank and allowing it to drop 25 times at rate of about one drop/second. During the operation, care is taken that the basket and aggregates remaining completely immersed in water. Afterwards they are kept in water for 24 hours. The basket and aggregates are then weighed in water and allowed to drain for a few minutes and then the aggregate is taken out from the basket and placed on dry cloth and 
surface is gently dried with the cloth. The aggregate is transferred to second dry cloth and further dried. The empty basket again immersed in water, jolted 25 times and weighed in water. The aggregate is exposed to atmosphere away from direct sun light for not less than 10 minutes until it appears completely surface dry. Then the aggregate is weighted in air. Afterwards, the aggregate is kept in the oven at temperatures of 100 to $1000^{\circ} \mathrm{C}$ and maintained at this temperature for $24(1 / 2)$ hours. It is then cooled off in the air tight container and weighed.

\section{RESULTS AND DISCUSSION}

\section{a) Test Conducted on Fresh and Hardened} Concrete.

The grade of concrete selected in this investigation was M25 as designated by IS: 456 (2000). Glass fibre added was $0.5 \%$ and $1.5 \%$ by volume of cement. Fly ash, when tested in accordance with the methods specified in IS: 1727 (1967) conformed to the chemical requirements.

Table: 1 Chemical Requirement [IS: 3812 (1981)]

\begin{tabular}{|l|l|l|}
\hline $\begin{array}{l}\text { S. } \\
\text { No }\end{array}$ & Characteristics & $\begin{array}{l}\text { Requiremen } \\
\text { ts } \\
(\%)\end{array}$ \\
\hline 1 & $\begin{array}{l}\text { (SiO2) }+(\mathrm{Al} 2 \mathrm{O} 3)+(\mathrm{Fe} 2 \mathrm{O} 3) \text { per } \\
\text { cent by mass, Min }\end{array}$ & 70.0 \\
\hline 2 & $(\mathrm{SiO} 2)$ per cent by mass, Min & 35.0 \\
\hline 3 & $(\mathrm{MgO})$ per cent by mass, Max & 5.0 \\
\hline 4 & $\begin{array}{l}\text { Sulphur trioxide (SO3) per cent by } \\
\text { mass, Max }\end{array}$ & 2.75 \\
\hline 5 & $\begin{array}{l}\text { Sodium oxide (Na2O) per cent by } \\
\text { mass, Max }\end{array}$ & 1.5 \\
\hline 6 & LOl per cent by mass, Max & 12.0 \\
\hline
\end{tabular}

TABLE: 2 DATA FOR MIX PROPOTIONING:

\begin{tabular}{|l|l|l|}
\hline 1. & Grade designation & $:$ M25 \\
\hline 2. & Type of Cement & $\begin{array}{l}: \text { OPC 43 grade } \\
\text { confirming to IS:8112 }\end{array}$ \\
\hline 3. & $\begin{array}{l}\text { Maximum nominal size of } \\
\text { aggregates }\end{array}$ & $: 20 \mathrm{~mm}$ \\
\hline 4. & Minimum cement content & $: 300 \mathrm{~kg} / \mathrm{m}^{3}$ \\
\hline 5. & Workability & $: 50$ to $100 \mathrm{~mm}$ \\
\hline 6. & Exposure condition & $:$ Moderate \\
\hline 7. & Degree of supervision & $:$ Good \\
\hline 8. & Type of aggregate & $\begin{array}{l}: \text { Crushed angular } \\
\text { aggregate }\end{array}$ \\
\hline 9. & Maximum cement content & $: 450 \mathrm{~kg} / \mathrm{m}^{3}$ \\
\hline 10. & Chemical admixture type & $:$ Nil \\
\hline 11. & Compaction factor & $: 0.9$ \\
\hline
\end{tabular}

TABLE: 3 TESTED DATA FOR MATERIALS:

\begin{tabular}{|l|l|l|}
\hline 1. & Cement used & $:$ OPC 43 grade \\
\hline 2. & Specific gravity of cement & $: 3.15$ \\
\hline 3. & $\begin{array}{l}\text { Specific gravity of coarse } \\
\text { aggregate }\end{array}$ & $: 2.7$ \\
\hline 4. & Specific gravity of fine aggregate & $: 2.64$ \\
\hline 5. & $\begin{array}{l}\text { Water absorption of coarse } \\
\text { aggregate }\end{array}$ & $: 0.81 \%$ \\
\hline 6. & Water absorption of fine aggregate & $: 0.80 \%$ \\
\hline 7. & Grading of coarse aggregate & $: 2^{\text {nd }}$ grade \\
\hline 8. & Grading of fine aggregate & $: 2^{\text {nd }}$ grade \\
\hline
\end{tabular}

\section{b) TARGET STRENGTH FOR MIX} PROPORTIONING

$\mathrm{f}^{\prime}{ }_{\mathrm{ck}}=\mathrm{f}_{\mathrm{ck}}+1.65 \mathrm{~s}$

Where,

$\mathrm{f}^{\prime}{ }_{\mathrm{ck}}=$ Target average compressive strength at 28 days

$\mathrm{f}_{\mathrm{ck}}=$ Characteristic compressive strength at 28 days

$\mathrm{s}=$ Standard deviation .

Here, standard deviation, $\mathrm{s}=4 \mathrm{~N} / \mathrm{mm}^{2}$.

Therefore,

Target Strength $=25+(1.65 \times 4)=31.6 \mathrm{~N} / \mathrm{mm}^{2}$

\section{c) SELECTION OF WATER CEMENT RATIO:}

Maximum water cement ratio $=0.45$

Based on graph for the above target mean strength and OPC 43grade; Based on durability ratio

Water-Cement ratio $=$ minimum of $(0.43 ; 0.50)$

Therefore, Water-Cement ratio $=0.43$

\section{d) Compaction Factor Test}

The compaction factor test was carried out as per IS: 1199 (1959) and the recommended values are given in Table. It is more precise and sensitive than the slump test and is particularly useful for concrete mixes of very low workability, as they are normally used when concrete is to be compacted by vibration.

Compaction Factor $=\frac{\text { Weight of partially compacted concrete }}{\text { Weight of fully compacted concrete }}$

Table: 4 Recommended values for compaction factor test

\begin{tabular}{|l|l|}
\hline Compaction Factor & Workability \\
\hline 0.85 & Low or Poor \\
\hline 0.92 & Medium \\
\hline 0.95 & Good \\
\hline
\end{tabular}

Table: 5 Results of workability tests on concrete

\begin{tabular}{|l|l|l|l|}
\hline Type of concrete & $\begin{array}{l}\text { Slump } \\
\text { value } \\
\text { mm }\end{array}$ & $\begin{array}{l}\text { Compaction } \\
\text { Factor }\end{array}$ & Remarks \\
\hline $\begin{array}{l}\text { Conventional } \\
\text { concrete without } \\
\text { fibre }\end{array}$ & 81 & 0.91 & Workable \\
\hline $\begin{array}{l}\text { Glass fibre } \\
\text { concrete with } \\
0.5 \% \text { fibre fibre }\end{array}$ & 86 & 0.87 & Workable \\
\hline $\begin{array}{l}\text { Glass fibre } \\
\text { concrete with 1\% } \\
\text { of fibre with }\end{array}$ & 88 & 0.88 & Workable \\
\hline $\begin{array}{l}\text { Glass } \\
\text { concrete } \\
1.5 \% \text { of fibre }\end{array}$ & & \\
\hline
\end{tabular}




\section{e) COMPRESSIVE STRENGTH:}

Out of numerous tests conducted to the solid, this is the most extreme essential which gives a thought regarding every one of the attributes of cement. By this single test one can judge that whether Concreting has been done appropriately or not. For solid shape test two sorts of examples either 3D squares of $15 \mathrm{~cm} \mathrm{X} 15 \mathrm{~cm} \mathrm{X} 15 \mathrm{~cm}$ or $10 \mathrm{~cm} \times 10 \mathrm{~cm} \times 10 \mathrm{~cm}$ relying on the measure of total are utilized. For the majority of the works cubical moulds of size $15 \mathrm{~cm} \times 15 \mathrm{~cm} \times 15 \mathrm{~cm}$ are normally utilized. The glass fibres are included at the rate of $0.5 \%, 1 \%, 2 \%$ and $3 \%$ of cement. This solid is poured in the mould and altered legitimately so as not to have any voids. Following 24 hours these moulds are evacuated and test examples are placed in water for curing. These examples are tried by pressure testing machine following 7 days curing or 28 days curing. Burden ought to be connected steadily at the rate of $140 \mathrm{~kg} / \mathrm{cm} 2$ every moment till the Specimens fizzles. Load at the disappointment isolated by zone of example gives the compressive quality of cement. Compressive Strength $(\mathrm{Mpa})=$ Failure load/Cross sectional area.

Table: 6 compressive strength

\begin{tabular}{|l|l|l|l|}
\hline \multirow{2}{*}{ S.NO } & \multirow{2}{*}{$\begin{array}{l}\text { M20 + Glass } \\
\text { fibre }\end{array}$} & $\begin{array}{l}\text { Compressive } \\
\left(\mathrm{N} / \mathrm{mm}^{2}\right)\end{array}$ \\
\cline { 3 - 4 } & & 7 days & 28 days \\
\hline 1. & $0.5 \%$ & 17.7 & 27.06 \\
\hline 2. & $1 \%$ & 20.76 & 28.46 \\
\hline 3. & $2 \%$ & 19.64 & 26.98 \\
\hline 4. & $3 \%$ & 18.4 & 26.108 \\
\hline
\end{tabular}

f) Effect of Compressive strength on Glass Fiber Concrete.

This figure represents the graph between the Compressive strength vs. $\%$ of glass fibre. The glass fibre is added at the rate of $0.5 \%, 1 \%, 2 \%$, and $3 \%$. Out of these, the compressive strength is very high at $1 \%$ having for 7 days is $20.76 \mathrm{~N} / \mathrm{mm}^{2}$ and for 28 days is $28.46 \mathrm{~N} / \mathrm{mm}^{2}$

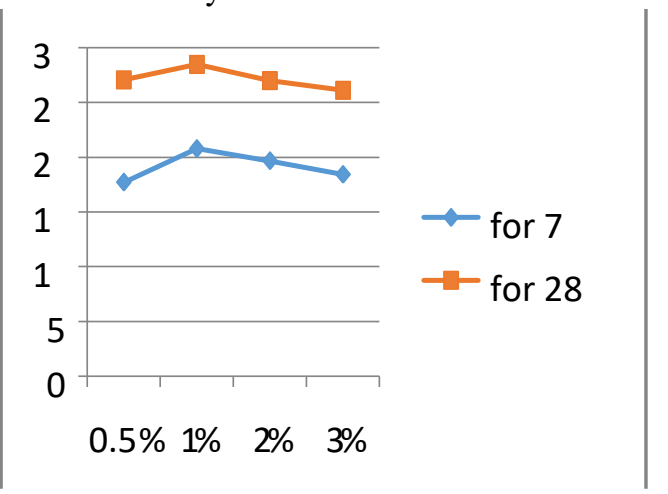

Fig1: Compressive strength vs. \% of glass fiber

\section{g) SPLIT TENSILE STRENGTH:}

To locate the split elasticity the barrels were placed in the moulds of measurements $300 \mathrm{~mm}$ length and $150 \mathrm{~mm}$ diameter across with M20 grade concrete. Set up the test example by including the glass fibre at the rate of $0.5 \%$,
$1 \%, 2 \%, 3 \%$ were additionally included. While placing the barrels the compaction is done utilizing the table vibrator. Finally the top layer of the example is completely levelled and very much wrapped up. From time of casting 24 hours the barrels were demoulded and were kept for curing in curing tank for 28days. After 28days curing is done these examples have been tried in pressure testing machine. The split rigidity is figured as takes after.

Split tensile strength $(\mathrm{Mpa})=2 p / \pi D l$

$\mathrm{P}=$ Failure load

$\mathrm{D}=$ Diameter of Cylinder

$\mathrm{L}=$ Length of cylinder.

Table: 7 Split tensile strength

\begin{tabular}{|l|c|c|c|}
\hline \multirow{2}{*}{$\begin{array}{l}\text { S. } \\
\text { NO }\end{array}$} & \multirow{3}{*}{ M20 + Glass fibre } & \multicolumn{2}{|c|}{ Split tensile strength $\left(\mathrm{N} / \mathrm{mm}^{2}\right)$} \\
& & \multicolumn{2}{|c|}{} \\
\hline & & 7 days & 28 days \\
\hline 1. & $0.5 \%$ & 1.41 & 3.4 \\
\hline 2. & $1 \%$ & 2.83 & 3.92 \\
\hline 3. & $2 \%$ & 2.62 & 3.57 \\
\hline 4. & $3 \%$ & 2.43 & 3.42 \\
\hline
\end{tabular}

h) Effect of Split Tensile strength on Glass Fiber Concrete

This figure represents the graph between the Split Tensile strength vs $\%$ of glass fibre. The glass fibre is added at the rate of $0.5 \%, 1 \%, 2 \%$, and $3 \%$. Out of these, the split tensile strength is very high at $1 \%$ having for 7 days is $2.83 \mathrm{~N} / \mathrm{mm}^{2}$ and for 28 days is $3.92 \mathrm{~N} / \mathrm{mm}^{2}$.

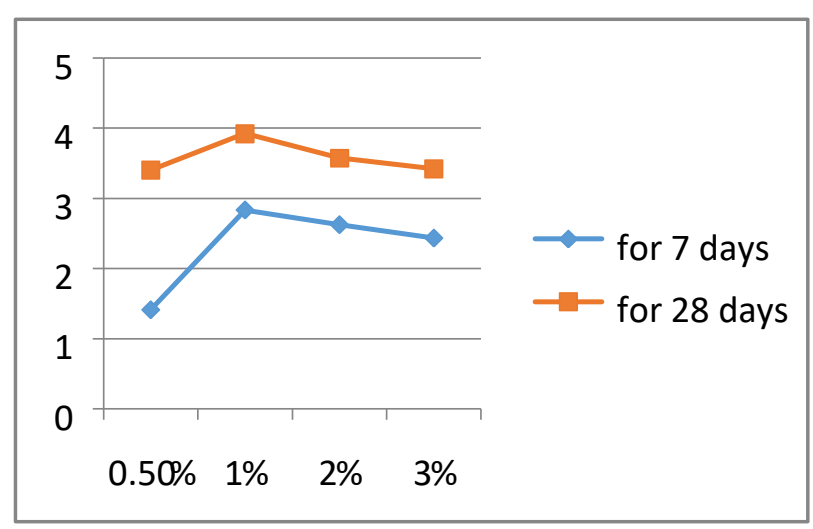

Fig2: Split Tensile strength vs. \% of glass fibre

\section{CONCLUSION AND FUTURE SCOPE}

- The slump value for concretes with glass fiber content. There is a systematic increase in slump as the glass fiber in the mix increases. The slump ranged from around $40 \mathrm{~mm}$ for the reference mix (i.e. $0 \%$ glass fiber) to $160 \mathrm{~mm}$ at $3 \%$ glass fiber.

- In compressive strength test, the glass fibre is added at the rate of $0.5 \%, 1 \%, 2 \%$, and $3 \%$. Out of 
these, the compressive strength is very high at $1 \%$ having for 7 days is $20.76 \mathrm{~N} / \mathrm{mm} 2$ and for 28 days is $28.46 \mathrm{~N} / \mathrm{mm}^{2}$.

- In split tensile test,the glass fibre is added at the rate of $0.5 \%, 1 \%, 2 \%$, and $3 \%$. Out of these, the split tensile strength is very high at $1 \%$ having for 7 days is $2.83 \mathrm{~N} / \mathrm{mm} 2$ and for 28 days is $3.92 \mathrm{~N}$ $/ \mathrm{mm}^{2}$

- In acid curing, compressive strength is decreasing compare to normal curing compressive strength. In this test $0.45 \mathrm{w} / \mathrm{c}$ ratio gives higher strength than $0.5 \mathrm{w} / \mathrm{c}$ ratio. $0.2 \% \mathrm{VF}$ gives higher strength result in both water cement ratio.

- In 7 days acid curing test, $0.5 \mathrm{w} / \mathrm{c}$ ratio gives higher strength compare to $0.45 \mathrm{w} / \mathrm{c}$. compressive strength of glass fiber is decreasing compare to M25 normal concrete in $0.45 \mathrm{w} / \mathrm{c}$ ratio but in 0.5 w/c ratio, the compressive strength of glass fiber increase than the normal concrete.

- In 28 days acid curing, compressive strength is decreasing compare to normal curing compressive strength. In this test $0.45 \mathrm{w} / \mathrm{c}$ ratio gives higher strength than $0.5 \mathrm{w} / \mathrm{c}$ ratio. $0.2 \% \mathrm{VF}$ gives higher strength result in both water cement ratio.

- Utilization of waste glass in concrete will keep natural resources, particularly river sand and therefore constitute the concrete construction industry sustainable.

- With the substitution of waste glass fiber the compressive strength gets improved considerably.

- Utilization of waste glass in concrete can turn out to be economical as it is no useful waste and spare of cost.

\section{FUTURE SCOPE}

- Further study can be carried out using different percentage of using waste glass fiber and determining the optimum percentage of glass waste to achieve compressive strength and split tensile strength
- Glass fiber can be introduced in concrete.

- Study on replacing coarse aggregate with glass pieces can be carried out

- Different type of glass fiber can be used.

- Replacement of cement with glass fiber with different water cement ratio

- Test for other properties of concrete for other concrete grade can be carried out.

\section{REFERENCES}

[1] Adarsh Dubey (2016) Sanjay Saraswat and Devansh Jain; Study of Properties of Concrete when its Fine Aggregate is replaced by Glass Fiber,IJSRD - International Journal for Scientific Research \& Development| Vol. 2, Issue 08, 2014 | page 10-12 | ISSN (online): 2321-0613.

[2] Khatib JM, Negim EM, Sohl HS, Chileshe N.(2014) Glass fiber utilisation in concrete production. Eur J Appl Sci 2012;4(4):1736.

[3] Madandoust Rahmat, Ghavidel Reza.(2013). Mechanical properties of concrete containing waste glass fiber and rice husk ash. Biosyst Eng 2013; 116(2): 113-9.

[4] Balandis A, Vaickelionis G. Stiklo defektuz (2012) susijusiuz su stiklo duz enuz naudojimu Iz krovoje, analyze. ISSN 1392-1231. CHEMINE` TECHNOLOGIJA. 2012. Nr. 1(59)

[5] Mageswari M, Vidivelli B. (2010) The use of sheet glass fiber as fine aggregate replacement in concrete. Open Civil Eng J 2010, $4: 65-71$

[6] Shi, C. and K. Zheng, (2007). Resources, Conservation and Recycling, 52(2): 5-40

[7] Sobolev K., Turker P., Soboleva S., Iscioglu G., (2006) "Utilization of waste glass in ECO-cement: strength properties and micro structural observations," Waste Management 27 (7), 971-976.

[8] V. Corinaldesi, G. Gnappi, G. Moriconi, and A. Montenero, (2005) "Reuse of ground waste glass as aggregate for mortars", Waste Management, vol.2, pp.197-201, Jan.2005

[9] Ahmad Shayan (2004) "Value Added Utilization of Waste Glass in Concrete" IABSE Symposium Melbourne, 2002, p.p.1-12.

[10] Chesner W.H, Coollins (1998) R.J \& Mackay M.H, User Guidelines for Waste and By-product Materials in Pavemen Construction, U.S. Department of Transportation, Federal Highway Administration, Publication No. FHWA-RD-97-148, 1997.

[11] REPLACEMENT OF CEMENT IN CONCRETE International Journal of Emerging Trends in Engineering and Development Issue 5, Vol.1 (Dec.-Jan 2015) 